\title{
Spectrally weighted transparency in models of water-column photosynthesis and photoinhibition by ultraviolet radiation
}

\author{
Moritz K. Lehmann*, Richard F. Davis, Yannick Huot, John J. Cullen \\ Centre for Marine Environmental Prediction (CMEP), Department of Oceanography, Dalhousie University, Halifax, \\ Nova Scotia B3H 4J1, Canada
}

\begin{abstract}
We present a simple method for describing the influence of variable attenuation of spectral irradiance, $K_{\mathrm{d}}(\lambda)$, on water-column photosynthesis and its inhibition by ultraviolet radiation (UV). The approach is based on weighted water transparency, a calculation introduced by Vincent et al. 1998 (Ann Glaciol 27:691-696). Key results of a depth- and spectrally-resolved model of photosynthesis can be reproduced for a broad range of water types by simple parameterizations using a reference solar irradiance spectrum at the surface and water transparency $\left[1 / K_{\mathrm{d}}(\lambda)\right]$ weighted spectrally for biological effectiveness. Transparency that has been weighted spectrally by the normalized product of irradiance and photosynthetic absorption (PUR-weighted transparency, $T_{\mathrm{PUR}}^{\mathrm{W}}$ ) describes spectral effects on photosynthesis in the water column. An empirical parameterization of transparency weighted by the product of surface irradiance and the biological weighting function for inhibition of photosynthesis $\left(T_{\mathrm{PIR}}^{\mathrm{W}}\right)$, along with $T_{\mathrm{PUR}}^{\mathrm{W}}$, describes the inhibition of water-column photosynthesis relative to the uninhibited rate. Our approach is directly compared with an analysis that used weighted transparency as an indicator of the potential for inhibition of photosynthesis by UV as influenced by variations in chromophoric dissolved organic matter associated with climate change over the past 6000 yr (Pienitz \& Vincent 2000, Nature 404:484-487). Results demonstrate how weighted transparency, used as an indicator of potential inhibition, can be transformed into a predictor of biological effects.
\end{abstract}

KEY WORDS: Weighted transparency - Photosynthesis model - Photoinhibition - Attenuation · Optical properties $\cdot$ CDOM

\section{INTRODUCTION}

In models of depth-integrated primary production, the rate of photosynthesis depends on the concentration of chlorophyll, surface irradiance, and the penetration of solar irradiance with depth. In the simplest case, water-column photosynthesis per unit surface area, $\int P\left(\mathrm{mg} \mathrm{C} \mathrm{m}^{-2} \mathrm{~h}^{-1}\right)$, is a function of irradiance at the surface, integrated between 400 and $700 \mathrm{~nm}$ (photosynthetically active radiation, $E_{\mathrm{PAR}}$ cf. Talling 1957$)$, and its penetration is expressed as the nominal depth of the euphotic zone, $z_{\mathrm{eu}}(\mathrm{PAR})(\mathrm{m})$, commonly defined as the depth at which $E_{\mathrm{PAR}}$ is $1 \%$ of its value at the surface (Ryther \& Yentsch 1957, Talling 1957, Platt \&
Sathyendranath 1993, and review by Behrenfeld \& Falkowski 1997):

$$
\int P=P_{\max }^{\mathrm{B}} \cdot B \cdot z_{\mathrm{eu}}(\mathrm{PAR}) \cdot f\left(\frac{E_{\mathrm{PAR}}\left(0^{-}\right)}{E_{\mathrm{k}}(\mathrm{PAR})}\right)
$$

where $P_{\max }^{\mathrm{B}}$ is the maximum rate of photosynthesis normalized to chlorophyll (mg C $\left[\mathrm{mg} \mathrm{chl}^{-1} \mathrm{~h}^{-1}\right.$ ), $B$ (mg

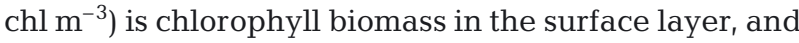
the dependence on irradiance is described as a function of $E_{\mathrm{PAR}}$ just below the surface, $E_{\mathrm{PAR}}\left(0^{-}\right)$, divided by the saturation parameter for photosynthesis in units of PAR irradiance, $E_{\mathrm{k}}(\mathrm{PAR})$. Direct measurements should be used to constrain $z_{\mathrm{eu}}(\mathrm{PAR})$; alternatively, $z_{\mathrm{eu}}(\mathrm{PAR})$ has been related to total phytoplankton pigment in the 
Table 1. Symbols, units and definitions

\begin{tabular}{|c|c|c|}
\hline Symbol & Units & Description \\
\hline$a_{\mathrm{n}}, b_{\mathrm{n}}, c_{\mathrm{n}}$ & & $\begin{array}{l}\text { Parameters of power functions to estimate results of photosynthesis } \\
\text { model; } n=\{1,2\} \text { for } a \text {, and } n=\{1,2,3\} \text { for } b \text { and } c\end{array}$ \\
\hline$a_{\mathrm{p}}(\lambda)$ & $\mathrm{m}^{-1}$ & Spectral absorption coefficient of phytoplankton \\
\hline $\bar{a}_{\mathrm{p}}$ & $\mathrm{m}^{-1}$ & Mean absorption coefficient of phytoplankton over 400 to $700 \mathrm{~nm}$ \\
\hline$B$ & $\mathrm{mg} \mathrm{chl} \mathrm{m}{ }^{-3}$ & Chlorophyll concentration \\
\hline$E_{\mathrm{k}}$ & $\mu \mathrm{mol}$ quanta $\mathrm{m}^{-2} \mathrm{~s}^{-1}$ & Saturation parameter for photosynthesis \\
\hline$E_{\mathrm{PAR}}\left(0^{-}\right)$ & $\mu \mathrm{mol}$ quanta $\mathrm{m}^{-2} \mathrm{~s}^{-1}$ & $\begin{array}{l}\text { Scalar irradiance just below the surface integrated over } 400 \text { to } \\
700 \mathrm{~nm}\end{array}$ \\
\hline$E_{\mathrm{PIR}}^{*}(Z)$ & (dimensionless) & Scalar irradiance weighted for inhibition of photosynthesis \\
\hline$E_{\mathrm{PUR}}(z)$ & $\mu \mathrm{mol}$ quanta $\mathrm{m}^{-2} \mathrm{~s}^{-1}$ & $\begin{array}{l}\text { Scalar irradiance weighted for absorption by photosynthetic } \\
\text { pigments }\end{array}$ \\
\hline$E_{\text {ref }}\left(0^{-}, \lambda\right)$ & $\mu \mathrm{mol}$ quanta $\mathrm{m}^{-2} \mathrm{~s}^{-1} \mathrm{~nm}^{-1}$ & Spectral scalar irradiance just below the water surface \\
\hline$E_{400}\left(0^{-}, \lambda\right)$ & (dimensionless) & $\begin{array}{l}\text { Spectral scalar irradiance just below the water surface normalized to } \\
1.0 \text { at } 400 \mathrm{~nm}\end{array}$ \\
\hline$F(\lambda)$ & (dimensionless) & Factor of enhancement in surface irradiance due to ozone depletion \\
\hline$K_{\mathrm{d}}(\lambda)$ & $\mathrm{m}^{-1}$ & Spectral diffuse attenuation coefficient \\
\hline$K_{\mathrm{PAR}}$ & $\mathrm{m}^{-1}$ & $\begin{array}{l}\text { Diffuse attenuation coefficient averaged over } 400 \text { to } 700 \mathrm{~nm} \text { from the } \\
\text { surface to the depth of } 1 \% \text { surface PAR }\end{array}$ \\
\hline$P_{\text {pot }}(z)$ & $\mathrm{mg} \mathrm{C} \mathrm{m}{ }^{-3} \mathrm{~h}^{-1}$ & Potential for primary production in the absence of inhibition \\
\hline$P(z)$ & $\mathrm{mg} \mathrm{C} \mathrm{m} \mathrm{m}^{-3} \mathrm{~h}^{-1}$ & Inhibited rate of photosynthesis \\
\hline $\int P$ & $\mathrm{mg} \mathrm{C} \mathrm{m} \mathrm{m}^{-2} \mathrm{~h}^{-1}$ & Water-column integrated rate of photosynthesis \\
\hline $\int P_{\text {pot }}^{*}$ & $\mathrm{~m}$ & $\begin{array}{l}\text { Water-column integrated potential rate of photosynthesis normalized } \\
\text { to } B \text { and } P_{\mathrm{s}}^{\mathrm{B}}\end{array}$ \\
\hline $\int P^{*}$ & $\mathrm{~m}$ & $\begin{array}{l}\text { Water-column integrated inhibited rate of photosynthesis normalized } \\
\text { to } B \text { and } P_{\mathrm{S}}^{\mathrm{B}}\end{array}$ \\
\hline$\Delta P / P_{\text {pot }}$ & (dimensionless) & $\begin{array}{l}\text { Proportion of water-column photosynthesis lost due to photo- } \\
\text { inhibition }\end{array}$ \\
\hline$P_{\max }^{\mathrm{B}}$ & $\mathrm{mg} \mathrm{C}[\mathrm{mg} \mathrm{chl}]^{-1} \mathrm{~h}^{-1}$ & $\begin{array}{l}\text { Maximum rate of primary production per unit chlorophyll in a } \\
\text { depth-integrated model }\end{array}$ \\
\hline$P_{\mathrm{s}}^{\mathrm{B}}$ & $\operatorname{mg~C}[\mathrm{mg} \mathrm{chl}]^{-1} \mathrm{~h}^{-1}$ & $\begin{array}{l}\text { Maximum attainable rate of primary production per unit chlorophyll } \\
\text { in the absence of photoinhibition }\end{array}$ \\
\hline$T_{\mathrm{PIR}}^{\mathrm{W}}$ & $\mathrm{m}$ & PIR-weighted transparency \\
\hline$T_{\mathrm{PUR}}^{\mathrm{W}}$ & $\mathrm{m}$ & PUR-weighted transparency \\
\hline$T_{\mathrm{PI}}^{*}$ & $\mathrm{~m}$ & PIR-weighted transparency according to Vincent et al. (1998) \\
\hline$z$ & $\mathrm{~m}$ & Depth below the water surface \\
\hline$z_{\text {eu }}(\mathrm{PAR})$ & $\mathrm{m}$ & Depth of $1 \% E_{\mathrm{PAR}}\left(0^{-}\right)$ \\
\hline$z_{\text {eu }}(\mathrm{PUR})$ & 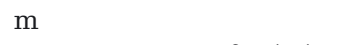 & Depth of $1 \% E_{\mathrm{PUR}}\left(0^{-}\right)$ \\
\hline$\varepsilon(\lambda)$ & $\left(\mu \mathrm{mol} \text { quanta } \mathrm{m}^{-2} \mathrm{~s}^{-1}\right)^{-1}$ & Biological weighting function for the inhibition of photosynthesis \\
\hline$\varepsilon_{300}(\lambda)$ & (dimensionless) & $\varepsilon(\lambda)$ normalized to 1.0 at $300 \mathrm{~nm}$ \\
\hline$\lambda$ & $\mathrm{nm}$ & Wavelength \\
\hline
\end{tabular}

water column (Morel \& Berthon 1989). See Table 1 for symbols and definitions.

Regardless of the exact formulation of the photosynthesis-light relationship, estimates of depth-integrated primary production are directly proportional to the depth of $1 \%$ surface $E_{\mathrm{PAR}}$. However, the use of $E_{\mathrm{PAR}}$ as the measure of light is a simplification. It has been recognized for decades that irradiance weighted for absorption by photosynthetic pigmentation (photosynthetically utilizable radiation, $E_{\mathrm{PUR}}$, Morel 1978; see Eq. 6) is more relevant than $E_{\mathrm{PAR}}$ as a measure of irradiance available for photosynthesis (e.g. Lewis et al. 1985, Morel 1991). Errors associated with the use of $E_{\mathrm{PAR}}$ rather than $E_{\mathrm{PUR}}$ are generally explored through the use of depth-resolved numerical models; they can be as large as $60 \%$ in waters with high chlorophyll concentration (Sathyendranath et al. 1989). Nonetheless, currently-used, depth-integrated models following the general form of Eq. (1) use $E_{\mathrm{PAR}}$ and $z_{\text {eu }}$ (PAR), perhaps because a simple parameterization of $z_{\mathrm{eu}}(\mathrm{PUR})$, the depth of $1 \%$ surface $E_{\mathrm{PUR}}$, has not been developed in this context.

More complete formulations of primary production (e.g. Arrigo 1994, Neale et al. 1998) take into account inhibition of photosynthesis as a function of biologically weighted UV radiation, i.e. photosynthesisinhibiting radiation, $E_{\text {PIR }}^{*}$ (see Neale 2000). This refinement is essential for describing the environmental 
effects of UV. For example, it provides a means to account for the influence of ozone depletion on watercolumn photosynthesis as well as natural variability of attenuation by UV-absorbing, chromophoric dissolved organic matter (CDOM) (Arrigo \& Brown 1996). Until the introduction of the approach described in this study (Lehmann et al. 2000, Neale 2001), no depthintegrated model of UV-inhibition existed; the effects of UV on depth-integrated photosynthesis could be evaluated quantitatively only through complicated numerical models (e.g. Arrigo et al. 2003).

Here, we show that well-recognized limitations of PAR-based models of depth-integrated primary productivity can be relieved by improving descriptions of the penetration of solar irradiance. We start with an approach pioneered by Vincent et al. (1998), who developed a straightforward method to assess the influence of variations in CDOM, and consequently the penetration of UV, on water-column photosynthesis. We extend their work by developing a novel parameterization of $z_{\text {eu }}$ (PUR) as a function of transparency, the inverse of the spectral diffuse attenuation coefficient for downwelling irradiance, which we weight spectrally for $E_{\text {PUR }}$. We then describe a straightforward relationship between weighted transparency and water-column photosynthesis as simulated by a spectral, depth-resolved model. Using a refinement of weighted transparency as developed by Vincent et al. (1998), we parameterize relative values of photoinhibition caused by UV radiation. To the best of our knowledge, this represents the first application of both photosynthetically utilizable radiation and inhibition of photosynthesis by UV in simple equations for estimating depth-integrated primary production.

As examples of practical applications of the parameterizations, we calculated the effects of variations in water-column transparency on photosynthetic production and the proportion of photoinhibition by UV using optical data from natural waters. Our approach is further explored in a re-analysis of data from an earlier application of weighted transparency using reconstructed optical properties for a sub-Arctic lake over the past 6000 yr (Pienitz \& Vincent 2000). Results demonstrate how weighted transparency, previously used as an indicator of potential inhibition, can be transformed into a predictor of biological effects.

\section{MATERIALS AND METHODS}

Overview of the approach. To describe the effects of variations in water transparency on water-column photosynthesis, we used a reference solar spectrum and a function relating water transparency to CDOM and chlorophyll to calculate depth-resolved spectral irradiance for 143 simulated water columns spanning a broad range of water types. For each case, 2 indices were constructed: transparency weighted for photosynthetically utilizable radiation, $T_{\text {PUR }}^{\mathrm{W}}(\mathrm{m})$, and transparency weighted for photosynthesis-inhibiting radiation, $T_{\mathrm{PIR}}^{\mathrm{W}}(\mathrm{m})$. Using a fully spectral numerical model, we calculated the rate of photosynthesis and its inhibition by UV as functions of depth for each water column. Resulting estimates of water-column photosynthesis, the uninhibited rate (i.e. without the inhibition term), and the fraction that is lost due to inhibition of photosynthesis were related quantitatively to $T_{\mathrm{PUR}}^{\mathrm{W}}$ and $T_{\mathrm{PIR}}^{\mathrm{W}}$ through statistically determined empirical functions. The resulting parameterizations, functions of $T_{\mathrm{PUR}}^{\mathrm{W}}$ and $T_{\mathrm{PIR}}^{\mathrm{W}}$, were then used to predict the influence of water transparency on photosynthesis and photoinhibition in natural bodies of water, using measurements in lakes and ocean water, and a reconstruction of optical properties in a sub-Arctic lake over the past 6000 yr (Pienitz \& Vincent 2000).

This approach has roots in the earliest depthintegrated models of primary production (e.g. Ryther \& Yentsch 1957, Talling 1957) and builds directly on the work of Vincent et al. (1998), who introduced weighted transparencies. The method was originally described by Lehmann et al. (2000), and aspects were incorporated into a study by Neale (2001).

Water types. Water types were characterized by individual attenuation spectra, $K_{\mathrm{d}}(\lambda)\left(\mathrm{m}^{-1}\right)$, constructed using a functional dependence of $K_{\mathrm{d}}(\lambda)$ on chlorophyll and dissolved organic matter (DOM) concentrations (Baker \& Smith 1982). Each of 11 chlorophyll concentrations $(0.02,0.05,0.1,0.5,1,2,3,4,5$, $10,15 \mathrm{mg} \mathrm{m}^{-3}$ ) was combined with each of 13 DOM concentrations ( 0 to $50 \mathrm{~g} \mathrm{~m}^{-3}$ ), yielding 143 distinct water types. These attenuation spectra were used to propagate through the water column a reference solar irradiance spectrum (280 to $700 \mathrm{~nm}$ ), modeled following Gregg \& Carder (1990), as extended into the UV range by Arrigo (1994). The irradiance spectrum is for a cloudless sky at $45^{\circ} \mathrm{N}$ on 21 March at noon, with an ozone content of 366.1 DU. Scalar irradiance just below the surface, $E_{\mathrm{ref}}\left(0^{-}, \lambda\right)$ ( $\mu \mathrm{mol}$ quanta $\mathrm{m}^{-2} \mathrm{~s}^{-1} \mathrm{~nm}^{-1}$ ), was calculated after Neale et al. (1998).

Weighted transparency. To obtain $T_{\text {PUR }}^{\mathrm{W}}(\mathrm{m})$, the transparency, $1 / K_{d}(\lambda)$, for each water type was weighted by the normalized phytoplankton absorption spectrum and scalar irradiance normalized to $E_{\mathrm{PAR}}$ :

$$
T_{\mathrm{PUR}}^{\mathrm{W}}=\sum_{400 \mathrm{~nm}}^{700 \mathrm{~nm}} \frac{1}{K_{\mathrm{d}}(\lambda)} \cdot \frac{a_{\mathrm{p}}(\lambda)}{\bar{a}_{\mathrm{p}}} \cdot \frac{E_{\mathrm{ref}}\left(0^{-}, \lambda\right)}{E_{\mathrm{PAR}}\left(0^{-}\right)} \cdot \Delta \lambda
$$

where

$$
E_{\mathrm{PAR}}\left(0^{-}\right)=\sum_{400 \mathrm{~nm}}^{700 \mathrm{~nm}} E_{\mathrm{ref}}\left(0^{-}, \lambda\right) \cdot \Delta \lambda
$$


( $\mu$ mol quanta $\mathrm{m}^{-2} \mathrm{~s}^{-1}$ ). We normalized photosynthetic absorption, $a_{\mathrm{p}}(\lambda)\left(\mathrm{m}^{-1}\right)$, by the mean absorption,

$$
\bar{a}_{\mathrm{p}}=\frac{1}{301} \sum_{400 \mathrm{~nm}}^{700 \mathrm{~nm}} a_{\mathrm{p}}(\lambda)
$$

$\left(\mathrm{m}^{-1}\right.$, where 301 is the number of wavelengths measured), so that in white light $E_{\mathrm{PUR}}=E_{\mathrm{PAR}}$ for any absorption spectrum (Markager \& Vincent 2001). Morel (1978) normalized $a_{\mathrm{p}}(\lambda)$ by the maximum absorption, consistent with the fact that not all light is utilized, i.e. $E_{\mathrm{PUR}}<E_{\mathrm{PAR}}$. We used an estimate of photosynthetic absorption derived from an excitation spectrum for in vivo chlorophyll fluorescence (Sakshaug et al. 1991).

Transparency was also weighted by the product of surface irradiance and a biological weighting function, $\varepsilon(\lambda)\left(\left[\mu \mathrm{mol} \text { quanta } \mathrm{m}^{-2} \mathrm{~s}^{-1}\right]^{-1}\right)$, which reflects the effectiveness of UV wavelengths in inhibiting photosynthesis of a marine diatom (Cullen et al. 1992). Summing over the UV and visible wavelengths (280 to $700 \mathrm{~nm}$ ) yields PIR-weighted transparency, $T_{\mathrm{PIR}}^{\mathrm{W}}(\mathrm{m})$ :

$$
T_{\mathrm{PIR}}^{\mathrm{W}}=\sum_{280 \mathrm{~nm}}^{700 \mathrm{~nm}} \frac{1}{K_{\mathrm{d}}(\lambda)} \cdot \varepsilon(\lambda) \cdot E_{\mathrm{ref}}\left(0^{-}, \lambda\right) \cdot \Delta \lambda
$$

Our formulation differs slightly from the one used by Vincent and colleagues (Vincent et al. 1998, Pienitz \& Vincent 2000), which, using our notation, is:

$$
T_{\mathrm{PIR}}^{*}=\frac{1}{111} \cdot \sum_{290 \mathrm{~nm}}^{400 \mathrm{~nm}} \frac{1}{K_{\mathrm{d}}(\lambda)} \cdot \varepsilon_{300}(\lambda) \cdot E_{400}\left(0^{-}, \lambda\right) \cdot F(\lambda) \cdot \Delta \lambda
$$

where $\varepsilon_{300}(\lambda)$ (dimensionless) is a biological weighting function (Cullen et al. 1992) normalized to equal 1.0 at $300 \mathrm{~nm}, E_{400}\left(0^{-}, \lambda\right)$ (dimensionless) is the reference spectrum of solar irradiance just below the water surface normalized to equal 1.0 at $400 \mathrm{~nm}, F(\lambda)$ is a dimensionless factor accounting for spectral changes of the irradiance from the reference spectrum due to ozone variability set to 1.0 for an ozone content of $330 \mathrm{DU}$, and $\Delta \lambda$ is $1 \mathrm{~nm}$. The factor $1 / 111\left(\mathrm{~nm}^{-1}\right)$ provides the average weighted transparency between 290 and $400 \mathrm{~nm}$; we inserted this term for dimensional consistency with $T_{\mathrm{PIR}}^{\mathrm{W}}$. The main difference between Eqs. (3) $\&(4)$ is that in our formulation, the weighting function and the irradiance spectrum are not normalized. In addition, $F(\lambda)$ has been dropped; instead, we used an irradiance spectrum appropriate for the ozone level studied. As a result, our weighted transparencies will not only be affected by the shape of the irradiance spectrum and weighting function but also by their absolute values. The latter is important when looking at changes caused by variations in the magnitude of solar spectra or when comparing different weighting functions of similar shapes, but different amplitudes (Neale 2000). In the present study, we evaluated only the in- fluence of water transparency on depth-integrated photosynthesis and its inhibition; effects of variations in solar spectra and weighting functions have previously been examined (Cullen et al. 2000) and will be reported elsewhere (J. J. Cullen et al. unpubl. data).

Numerical model of photosynthesis. Photosynthetic rates at solar noon were estimated for the 143 water types using a spectral model of photosynthesis and inhibition (Cullen et al. 1992), modified to use $E_{\mathrm{PUR}}$ instead of $E_{\mathrm{PAR}}$ as described by Neale et al. (1998). The uninhibited rate of photosynthesis (potential for photosynthesis, $\left.P_{\text {pot }}(z), \operatorname{mg~} \mathrm{C} \mathrm{m}^{-3} \mathrm{~h}^{-1}\right)$ at depth $z(\mathrm{~m})$ is modeled as a saturating function of irradiance, weighted for absorption by photosynthetic pigments $\left(E_{\mathrm{PUR}}(z)\right.$, umol quanta $\mathrm{m}^{-2} \mathrm{~s}^{-1}$ ):

$$
P_{\mathrm{pot}}(z)=B \cdot P_{\mathrm{s}}^{\mathrm{B}} \cdot\left(1-\mathrm{e}^{-\left(E_{\mathrm{PUR}}(z) / E_{\mathrm{k}}\right)}\right)
$$

where

$$
E_{\mathrm{PUR}}(z)=\sum_{400 \mathrm{~nm}}^{700 \mathrm{~nm}} \frac{a_{\mathrm{p}}(\lambda)}{\bar{a}_{\mathrm{p}}} \cdot E_{\mathrm{ref}}\left(0^{-}, \lambda\right) \cdot \mathrm{e}^{-K_{\mathrm{d}}(\lambda) \cdot z} \cdot \Delta \lambda
$$

The maximum attainable rate of photosynthesis, $P_{\mathrm{s}}{ }^{\mathrm{B}}$ (mg C $\left[\mathrm{mg} \mathrm{chl}^{-1} \mathrm{~h}^{-1}\right.$ ), was set to 1.0 so the numerical result for $P_{\text {pot }}(z)$ is equivalent to $P_{\text {pot }}(z) / P_{\mathrm{s}}$ (cf. Talling 1957). The saturation parameter for photosynthesis in terms of $E_{\text {PUR }}$, i.e. $E_{\mathrm{k}}$, was set to $150 \mu \mathrm{mol} \mathrm{m} \mathrm{m}^{-2} \mathrm{~s}^{-1}$. The concentration of chlorophyll, $B\left(\mathrm{mg} \mathrm{chl} \mathrm{m}^{-3}\right)$, was assumed uniform with depth, and its value was equal to that used to generate the corresponding attenuation spectrum for the water type.

After Cullen et al. (1992), the formulation of photosynthesis is extended to include inhibition as a function of the dose rate of photosynthesis-inhibiting radiation, $E_{\text {PIR }}^{*}$ (dimensionless), to give the inhibited rate of photosynthesis, $P(z)\left(\mathrm{mg} \mathrm{C} \mathrm{m}^{-3} \mathrm{~h}^{-1}\right)$ :

$$
P(z)=B \cdot P_{\mathrm{S}}^{\mathrm{B}} \cdot\left(1-\mathrm{e}^{-\left(E_{\mathrm{PUR}}(z) / E_{\mathrm{k}}\right)}\right) \cdot \frac{1}{1+E_{\mathrm{PIR}}^{*}(z)}
$$

where

$$
E_{\mathrm{PIR}}^{*}(z)=\sum_{280 \mathrm{~nm}}^{700 \mathrm{~nm}} \varepsilon(\lambda) \cdot E_{\mathrm{ref}}\left(0^{-}, \lambda\right) \cdot \mathrm{e}^{-K_{\mathrm{d}}(\lambda) \cdot z} \cdot \Delta \lambda
$$

Both $P_{\text {pot }}(z)$ and $P(z)$ were normalized to the product of $B$ and $P_{\mathrm{s}}{ }^{\mathrm{B}}$ then integrated numerically over 100 intervals, distributed evenly between the surface and $Z_{\text {eu }}(\mathrm{PUR})$, yielding normalized potential water-column photosynthesis, $\int P_{\text {pot }}^{*}(\mathrm{~m})$, and normalized inhibited water-column photosynthesis, $\int P^{*}(\mathrm{~m})$ :

$$
\begin{aligned}
\int P_{\mathrm{pot}}^{*} & =\frac{1}{P_{\mathrm{S}}^{\mathrm{B}} \cdot B} \int_{0}^{z_{\mathrm{eu}}(\mathrm{PUR})} P_{\mathrm{pot}}(z) \cdot \mathrm{d} z \\
\int P^{*} & =\frac{1}{P_{\mathrm{s}}^{\mathrm{B}} \cdot B} \int_{0}^{z_{\mathrm{eu}}(\mathrm{PUR})} P(z) \cdot \mathrm{d} z
\end{aligned}
$$


Because biomass and photosynthetic parameters are assumed uniform with depth, water-column photosynthesis $\left(\mathrm{mg} \mathrm{C} \mathrm{m}^{-2} \mathrm{~h}^{-1}\right)$ can be retrieved by multiplication of $\int P^{*}$ with the product of surface biomass and a suitable $P_{\mathrm{s}}^{\mathrm{B}}$.

The proportion of water-column photosynthesis lost due to inhibition, $\Delta P / P_{\text {pot }}$ (dimensionless), is:

$$
\Delta P / P_{\mathrm{pot}}=1-\frac{\int P^{*}}{\int P_{\mathrm{pot}}^{*}}
$$

Parameterizing the numerical calculations of photosynthesis. Normalized potential photosynthesis integrated over depth $\left(\int P_{\text {pot }}^{*}\right)$ was related to $T_{\mathrm{PUR}}^{\mathrm{W}}$, and both $\int P^{*}$ and the relative inhibition of photosynthesis $\left(\triangle P / P_{\text {pot }}\right)$ were related to $T_{\mathrm{PUR}}^{\mathrm{W}}$ and $T_{\mathrm{PIR}}^{\mathrm{W}}$ by simple parameterizations:

$$
\begin{aligned}
& \int P_{\mathrm{pot}}^{*}=a_{1} \cdot T_{\mathrm{PUR}}^{\mathrm{W}}{ }^{a_{2}} \\
& \int P^{*}=b_{1} \cdot T_{\mathrm{PUR}}^{\mathrm{W}} \cdot T_{\mathrm{PIR}}^{\mathrm{W}_{2} b_{3}} \\
& \Delta P / P_{\mathrm{pot}}=c_{1} \cdot T_{\mathrm{PUR}}^{\mathrm{W}} \cdot T_{\mathrm{PIR}}^{\mathrm{W}^{c_{3}}}
\end{aligned}
$$

The parameters $a_{n}$ to $c_{n}$ were determined for the 143 water types by nonlinear least-squares fits using the Gauss-Newton method (implemented in MATLAB). The units of $a_{1}, b_{1}$, and $c_{1}$ cancel out the awkward dimensionality resulting from fractional exponents for $T_{\mathrm{PUR}}^{\mathrm{W}}$ and $T_{\mathrm{PIR}}^{\mathrm{W}}$. The fit between the parameterization and the numerical simulation was evaluated by the coefficient of determination for a regression $\left(\mathrm{r}^{2}\right)$.

Application to natural waters. For a field application of the weighted transparency parameterizations, $T_{\mathrm{PUR}}^{\mathrm{W}}$ and $T_{\text {PIR }}^{\mathrm{W}}$ were calculated for $K_{\mathrm{d}}$ spectra from 6 lakes in Nova Scotia and from 7 stations, coastal and oceanic, in the North Atlantic. The lake spectra were measured during summer 1999 with a profiling radiometer (OCI-200, Satlantic) using 6 channels (323, 338, 380, 443,490 , and $555 \mathrm{~nm}$; with bandwidths of $2 \mathrm{~nm}$ at half maximum for the first 2 channels and $10 \mathrm{~nm}$ for the others). The depth profiles of downwelling irradiance from the 6 radiometer channels were corrected for the instrument dark signal to eliminate the artificial nonlinearity observed in plots of log-irradiance versus depth (Morrow \& Booth 1997). Then, attenuation coefficients for the 6 wavelengths were estimated by log-linear regression versus depth (Kirk 1994). The full attenuation spectrum between 280 and $700 \mathrm{~nm}$ was estimated by subtracting the contributions by chlorophyll and water (following the model of Baker \& Smith 1982, using chlorophyll measured fluorometrically on samples extracted in $90 \%$ acetone) from the $K_{\mathrm{d}}$-values at the channel wavelengths, then fitting the residual attenuation spectrum to an exponential function to describe attenuation by CDOM; the total attenuation spectrum was reconstructed by adding chlorophyll and water components back to the CDOM spectrum.

Marine irradiance profiles and chlorophyll concentrations were obtained from diverse water types during a cruise from Chesapeake Bay to the Gulf Stream in August 1997. Using a 13-channel profiling radiometer (SPMR, Satlantic, wavelengths 305, 325, 338, 380, 412, $443,490,510,532,555,670,683$, and $700 \mathrm{~nm})$, attenuation coefficients for the channel wavelengths 325 to $700 \mathrm{~nm}$ were estimated by log-linear regression versus depth. $K_{\mathrm{d}}$-values at 280 and $305 \mathrm{~nm}$, the latter an insufficiently sensitive channel of the SPMR, were estimated by extrapolating an exponential fit through the values at 325,338 , and $380 \mathrm{~nm}$. The entire spectrum was interpolated linearly between the channel wavelengths.

Using measured chlorophyll concentrations and attenuation spectra, $\int P^{*}$ and $\Delta P / P_{\text {pot }}$ were simulated the same way as for the modeled water columns.

Reconstruction of historic spectral transparency and relative photosynthesis. The second application of the weighted transparency parameterization used paleooptical data for Queen's Lake (sub-Arctic Canada, $\left.64^{\circ} 07^{\prime} \mathrm{N}, 110^{\circ} 34^{\prime} \mathrm{W}\right)$ from Pienitz \& Vincent (2000). Diffuse downwelling attenuation coefficients were reconstructed at four wavelengths in the UV according to an empirical relationship with dissolved organic carbon (DOC) concentrations estimated over the past $6000 \mathrm{yr}$ (Vincent et al. 1998). Clear-water attenuation (Baker \& Smith 1982) at those wavelengths was subtracted from the $K_{\mathrm{d}}(\lambda)$ values. The results were fitted to an exponential function of $K_{\mathrm{d}}(\lambda)$ versus DOC, then attenuation by clear water was added back to the entire spectrum to give an interpolation and extrapolation of $K_{\mathrm{d}}(\lambda)$ from 280 to $700 \mathrm{~nm}$. Assuming that absorption by chlorophyll contributed little to the empirical relationship between DOC and $K_{\mathrm{d}}(\lambda)$, which only considers UV wavelengths, we

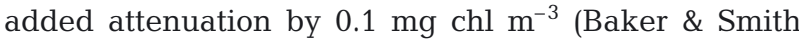
1982) to the reconstructed spectra to assess the contribution of chlorophyll. To comply with the analysis of Pienitz \& Vincent (2000), our parameterization was adapted to the sub-Arctic environment by using their reference solar irradiance spectrum (290 to $325 \mathrm{~nm}$ ) and extended it to 280 to $700 \mathrm{~nm}$ using a spectrum for that latitude from the irradiance model described above, scaled by the average ratio of the 2 spectra between 315 and $325 \mathrm{~nm}$.

\section{RESULTS AND DISCUSSION}

\section{Relationship between water-column photosynthesis and penetration of PUR}

A large number of models express water-column photosynthesis using variations of Eq. (1). Notation and details vary, but models predict that for a given surface 
irradiance, water-column photosynthesis, normalized to surface chlorophyll and a maximum rate of normalized photosynthesis (e.g. $\int P^{*}$, in meters), varies directly with a measure of light penetration. The depth of $1 \%$ surface PAR is a commonly used measure, and it is tempting to estimate it using the Lambert-Beer Law: $z_{\mathrm{eu}}(\mathrm{PAR})=4.6 / K_{\mathrm{PAR}}$, with $K_{\mathrm{PAR}}$ determined as the spectrally average $K_{\mathrm{d}}(\lambda)$ for surface water. This, however, produces large errors, as the attenuation of PAR changes with depth - it is high near the surface, and with depth it converges to the attenuation coefficient for the wavelength of maximum transmission (Kirk 1994). Furthermore, even with a $K_{\mathrm{PAR}}$ appropriately measured across the depth of the euphotic zone (Morel 1988 ), the shortcomings associated with using $E_{\mathrm{PAR}}$ instead of $E_{\mathrm{PUR}}$ remain (Lewis et al. 1985, Sathyendranath et al. 1989, Laws et al. 1990, Markager \& Vincent 2001).

We find that, in a uniform water column, the depth of $z_{\text {eu }}$ (PUR) can be predicted well by a nonlinear function of $T_{\mathrm{PUR}}^{\mathrm{W}}: z_{\mathrm{eu}}(\mathrm{PUR})=5.26 T_{\mathrm{PUR}}^{\mathrm{W}}{ }^{1.08}, \mathrm{r}^{2}=0.999, \mathrm{n}=143$ (Fig. 1A), using $K_{\mathrm{d}}(\lambda)$ from the surface. The simple power function is smooth and monotonic, and the sim-
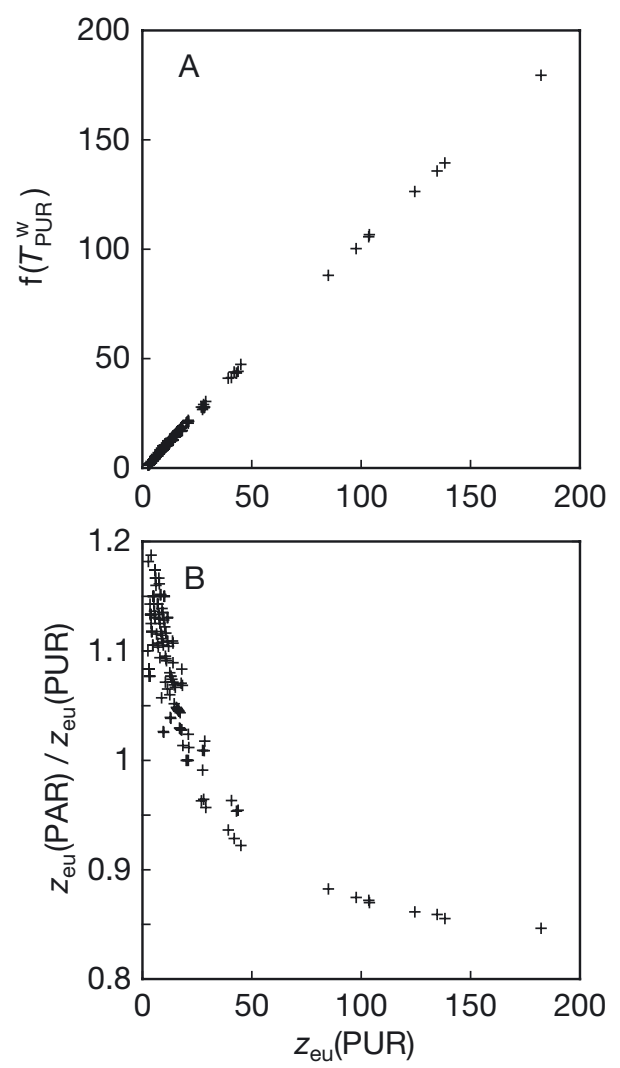

Fig. 1. (A) A simple power function of $T_{\text {PUR }}^{\mathrm{W}}$ predicts $z_{\text {eu }}$ (PUR): $z_{\text {eu }}(\mathrm{PUR})=5.26 T_{\mathrm{PUR}}^{\mathrm{W}}{ }^{1.08}, \mathrm{r}^{2}=0.999, \mathrm{n}=143$. (B) The ratio $z_{\text {eu }}(\mathrm{PAR}) / z_{\text {eu }}(\mathrm{PUR})$ for a given $z_{\text {eu }}(\mathrm{PUR})$. Each data point represents a water column with an individual $K_{\mathrm{d}}$ spectrum constructed after Baker \& Smith (1982) and a solar irradiance spectrum for $45^{\circ} \mathrm{N}$ ulated data points show little scatter despite the broad range of optical water types considered. Comparison of $z_{\text {eu }}(\mathrm{PAR})$ with $z_{\text {eu }}(\mathrm{PUR})$ illustrates the improvement (Fig. 1B). The ratio $z_{\text {eu }}(\mathrm{PAR}) / z_{\mathrm{eu}}$ (PUR) shows the error associated with using $E_{\mathrm{PAR}}$ rather than $E_{\mathrm{PUR}}$ to represent irradiance for photosynthesis in a depthintegrated model. For the broad range of water types considered, this error ranged from an underestimate of about $16 \%$ in very clear waters to an overestimate of nearly $20 \%$ in waters with relatively shallow euphotic depths. The implication is straightforward: in depthintegrated models of primary productivity, the expression of light penetration as a function of PUR-weighted transparency obviates the error associated with using $E_{\mathrm{PAR}}$ instead of $E_{\mathrm{PUR}}$ in the light-penetration term.

\section{General parameterization of uninhibited water-column photosynthesis}

Eq. (1) and the strong relationship between $z_{\text {eu }}(P U R)$ and $T_{\text {PUR }}^{\mathrm{W}}$ (Fig. 1A) suggest that for a given spectrum of solar irradiance at the surface, there should be a relationship between uninhibited water-column photosynthesis and $T_{\mathrm{PUR}}^{\mathrm{W}}$. Indeed, a simple power function of $T_{\text {PUR }}^{\mathrm{W}}$ could reproduce almost exactly the 143 calculations of $\int P_{\text {pot }}^{*}$ representing a broad range of water types $\left(\mathrm{r}^{2}=0.999, \mathrm{n}=143 ;\right.$ Table 2$)$ :

$$
\int P_{\mathrm{pot}}^{*}=2.91 \cdot T_{\mathrm{PUR}}^{\mathrm{W}}{ }^{1.09}
$$

\section{General parameterization of water-column photosynthesis as influenced by UV}

Existing PAR-based, depth-integrated models are inherently incapable of describing effects of UV on water-column photosynthesis. Currently, this can only be done through spectrally resolved numerical modeling (Arrigo 1994, Boucher \& Prézelin 1996, Neale et al. 1998). Inhibition-weighted transparency, $T_{\mathrm{PIR}}^{\mathrm{W}}$ quantifies the effect of UV on photosynthesis and its penetration with depth, so it was incorporated into a simple model similar to Eq. 15. The inhibited rate $\int P^{*}$ is described as a function of weighted transparencies:

$$
\int P^{*}=2.38 \cdot T_{\mathrm{PUR}}^{\mathrm{W}} \cdot T_{\mathrm{PIR}}^{\mathrm{W}^{-0.09}}
$$

As with Eq. (15), the simple function matched almost exactly the 143 results of numerical modeling $\left(\mathrm{r}^{2}=\right.$ 0.999, $\mathrm{n}=143$; Fig. 2C). In Eq. (16) the exponent of $T_{\mathrm{PIR}}^{\mathrm{W}}$, slightly greater than a value of 1 , compared to almost 0 for $T_{\mathrm{PIR}}^{\mathrm{W}}$, indicates that most of the variability in water-column photosynthesis is explained by $T_{\mathrm{PUR}}^{\mathrm{W}}$ alone $\left(\mathrm{r}^{2}=0.997, \mathrm{n}=143\right.$; Fig. 2A). In essence, when 
Table 2. Parameters of the power functions constructed to estimate water-column photosynthesis (Eqs. 12 \& 13) and the proportion of inhibition for different latitudes (Eq. 14). For each function, $r^{2}$ is the proportion of variability explained in the results of 143 numerical simulations

\begin{tabular}{|c|c|c|}
\hline \multirow{2}{*}{ Parameter } & \multicolumn{2}{|c|}{ - Latitude } \\
\hline & $45^{\circ} \mathrm{N}$ & Sub-Arctic \\
\hline$a_{1}$ & 2.91 & 2.72 \\
\hline & 1.09 & 1.09 \\
\hline$\left(\mathrm{r}^{2}\right)$ & $(0.999)$ & (0.999) \\
\hline$b_{1}$ & 2.38 & 2.24 \\
\hline$b_{2}$ & 1.19 & 1.18 \\
\hline & -0.09 & -0.08 \\
\hline$\left(\mathrm{r}^{2}\right)$ & (0.999) & $(0.998)$ \\
\hline$C_{1}$ & 0.24 & 0.26 \\
\hline$C_{2}$ & -1.08 & -1.07 \\
\hline$C_{3}$ & 1.01 & 1.00 \\
\hline$\left(r^{2}\right)$ & $(0.998)$ & (0.998) \\
\hline
\end{tabular}

only the influences of different water types are considered, changes in the penetration of $E_{\text {PUR }}$ play a much bigger role than photoinhibition in determining the variability of water-column production. Interestingly, since attenuation coefficients for UV wavelengths covary strongly with those in the visible range, $T_{\mathrm{PIR}}^{\mathrm{W}}$ explains $95.5 \%$ of the variability in $\int P^{*}\left(\mathrm{r}^{2}=0.955, \mathrm{n}=\right.$ 143; Fig. 2B).

\section{Proportional inhibition of water-column photosynthesis by UV}

Studies of UV radiation and aquatic photosynthesis focus primarily on estimating the proportional reduc- tion of photosynthesis due to UV (e.g. Smith et al. 1980). This inhibition is only a small fraction of $\int P_{\text {pot }}^{*}$ for the wide range of water types considered (Fig. 3), and neither $T_{\mathrm{PUR}}^{\mathrm{W}}$ nor $T_{\mathrm{PIR}}^{\mathrm{W}}$ can describe it precisely ( $T_{\mathrm{PUR}}^{\mathrm{W}}$ : $\mathrm{r}^{2}=0.172, \mathrm{n}=143 ; T_{\mathrm{PIR}}^{\mathrm{W}}: \mathrm{r}^{2}=0.630, \mathrm{n}=143$; Fig. 3A and $B$, respectively). In analogy to Eq. (16), proportional inhibition of water-column photosynthesis, $\Delta P / P_{\text {pot, }}$ is described very well $\left(\mathrm{r}^{2}=0.998, \mathrm{n}=143\right)$ by $\mathrm{a}$ combination of $T_{\mathrm{PUR}}^{\mathrm{W}}$ and $T_{\mathrm{PIR}}^{\mathrm{W}}$ (Fig. 3C):

$$
\Delta P / P_{\mathrm{pot}}=0.24 \cdot T_{\mathrm{PUR}}^{\mathrm{W}}{ }^{-1.08} \cdot T_{\mathrm{PIR}}^{\mathrm{W}}{ }^{1.01}
$$

The exponents in Eq. (17) are close to -1.0 and 1.0, indicating that the inhibition of water-column photosynthesis is strongly related to the ratio of $T_{\mathrm{PIR}}^{\mathrm{W}}$ to $T_{\mathrm{PUR}}^{\mathrm{W}}$ $\left(\mathrm{r}^{2}=0.998, \mathrm{n}=143\right)$ as found by Neale (2001), who adapted this approach (see also Fig. 5). The simple parameterizations (Eqs. 16 \& 17) are vastly easier to use and inherently more general than sensitivity analyses of numerical models of photosynthesis and photoinhibition.

\section{Estimates of photosynthesis and photoinhibition using measured $K_{d}$ spectra}

Weighted transparency and the numerical solutions for $\int P^{*}$ and $\Delta P / P_{\text {pot, }}$ all constrained with measured attenuation spectra and chlorophyll concentrations, compare well with relationships for the modeled water columns (circles and squares in Figs. 2 \& 3). This is notable since it implies that the parameterization is not restricted to attenuation spectra specified by a particular model of $K_{\mathrm{d}}(\lambda)$ as a function of CDOM and chlorophyll.
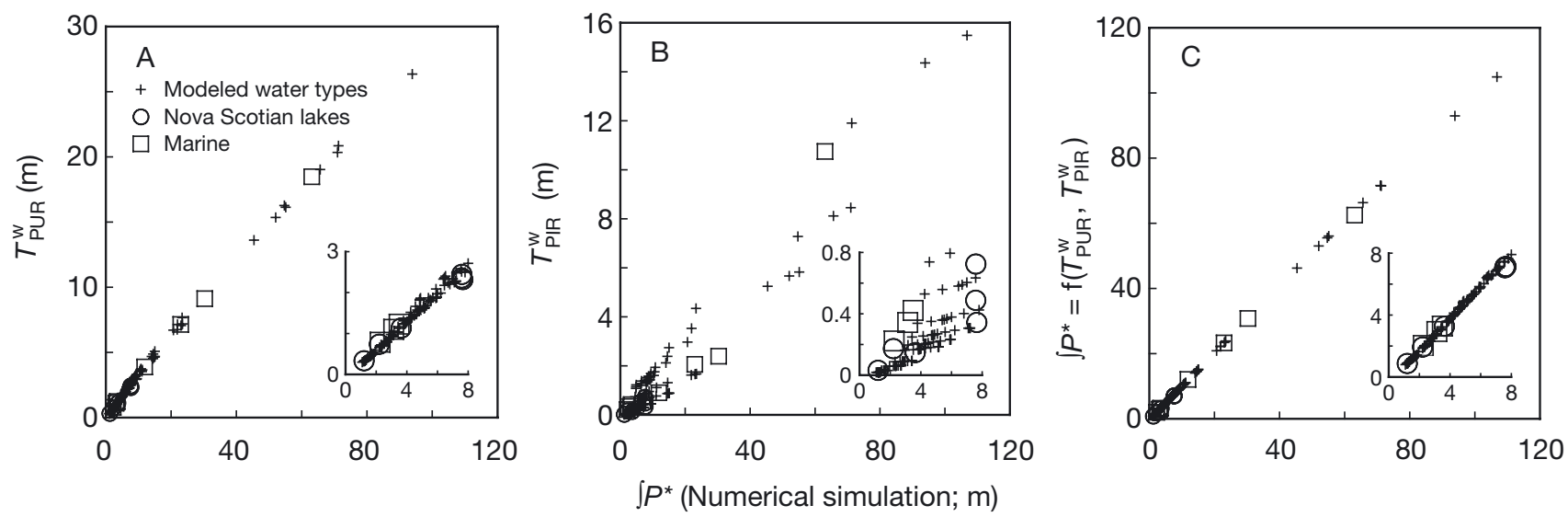

Fig. 2. (A) PUR-weighted transparency, $T_{\mathrm{PUR}}^{\mathrm{W}}$, is linearly proportional to the numerical solution for the normalized water-column integral of inhibited photosynthesis, $\int P^{*}\left(\mathrm{r}^{2}=0.997, \mathrm{n}=143\right)$. (B) PIR-weighted transparency, $T_{\mathrm{PIR}}^{\mathrm{W}}$, is related to $\int P^{*}\left(\mathrm{r}^{2}=0.955\right.$, $\mathrm{n}=143$ ). (C) A non-linear function of $T_{\mathrm{PUR}}^{\mathrm{W}}$ and $T_{\mathrm{PIR}}^{\mathrm{W}}$ (Eq. 13 with parameters $b_{n}$ for $45^{\circ} \mathrm{N}$ from Table 2) describes variability in inhibited water-column photosynthesis normalized to biomass $\left(\mathrm{r}^{2}=0.999, \mathrm{n}=143\right)$. Open circles and squares are added for comparison and represent results where measurements of $K_{\mathrm{d}}(\lambda)$ were used to predict $\int P^{*}$ in Nova Scotian lakes and marine systems, respectively 

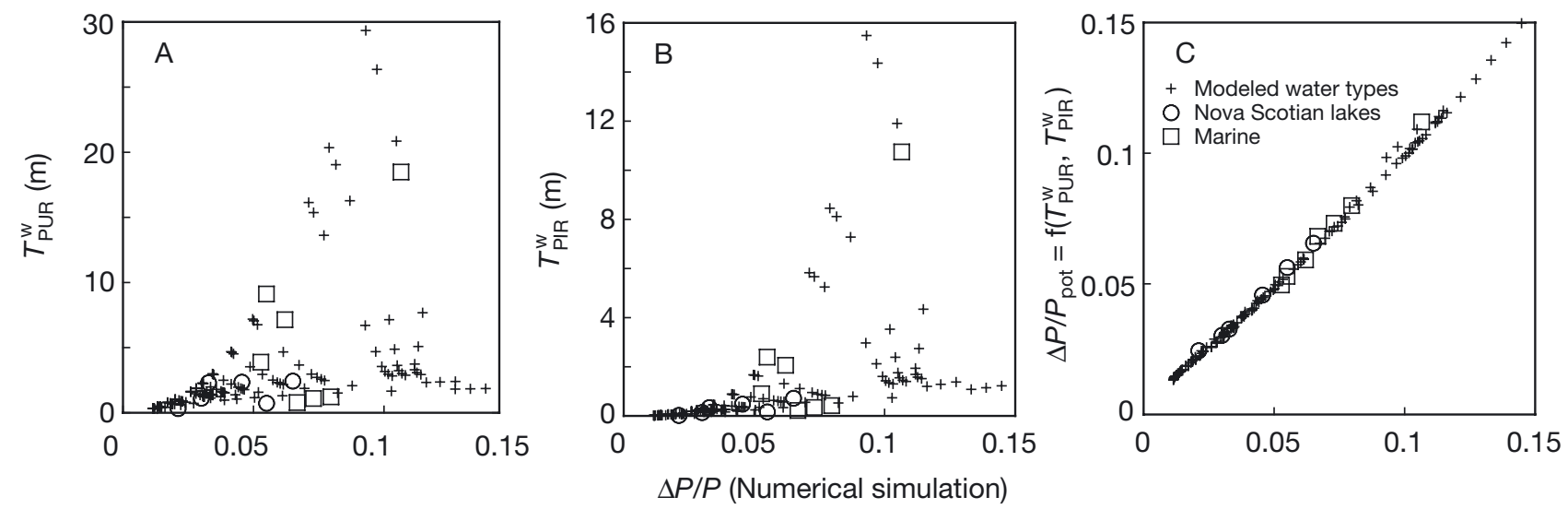

Fig. 3. (A, B) Relationship between the fraction of photosynthesis lost to inhibition, $\Delta P / P_{\text {pot, }}$ simulated numerically from a spectral model, and PUR- or PIR-weighted transparency $\left(\mathrm{r}^{2}=0.187\right.$ and $\left.\mathrm{r}^{2}=0.233, \mathrm{n}=143\right)$, respectively. (C) Prediction of $\Delta P / P$ pot by a parameterization of PUR- and PIR-weighted transparency (Eq. 14 with parameters $C_{n}$ for $45^{\circ} \mathrm{N}$ from Table $2, \mathrm{r}^{2}=0.998$, $\mathrm{n}=143$ ). Open circles and squares are added for comparison and represent results where measurements of $K_{\mathrm{d}}(\lambda)$ were used to constrain predictions of $\Delta P / P_{\text {pot }}$ in Nova Scotian lakes and marine systems, respectively

\section{Reconstruction of historic relative photosynthesis and inhibition}

The parameterizations for photosynthesis using the sub-Arctic irradiance spectrum (Eqs. 12, 13 \& 14, with coefficients in Table 2) were used to infer changes in $\int P^{*}$ and $\Delta P / P_{\text {pot }}$ due to optical variability in a generic, deep lake with the same historical evolution of optical properties as Queen's Lake in northern Canada. For the time-series records (Fig. 4), $\int P^{*}$ was multiplied by

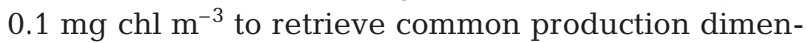
sions, assuming $P_{\mathrm{s}}^{\mathrm{B}}=1 \mathrm{mg} \mathrm{C}[\mathrm{mg} \mathrm{chl}]^{-1} \mathrm{~h}^{-1}$. While the inferred rate of photosynthesis and $\Delta P / P_{\text {pot }}$ show the same trends as $T_{\text {PI }}^{*}$ reported by Pienitz \& Vincent (2000, their Fig. 2d), the $x$-axis of our Fig. 4 is a quantitative estimate of relative photosynthesis and of photoinhibition as influenced by variations in water transparency, while $T_{\text {PI }}^{*}$ is an indicator of the potential for photoinhibition with no explicit relationship to relative photoinhibition per se. As in the analysis of Pienitz \& Vincent, our estimates are based on the unrealistic assumptions that the weighting function for photoinhibition and, in our work, for chlorophyll concentration, absorption spectra, and photosynthetic parameters do not change over time. Nonetheless, the new quantitative context is useful for interpreting the reconstruction of optical conditions in terms of the ecological pressure associated with variations in UV. Our parameterization indicates that since the transparency minimum, $4.41 \times 10^{3} \mathrm{yr}$ before present, photosynthesis (assuming $0.1 \mathrm{mg} \mathrm{chl} \mathrm{m}^{-3}$ ) increased by $1040 \%$. In turn, the proportion of inhibition of photosynthesis increased by $255 \%$, to 0.069 from 0.027 . During the same interval, the Pienitz \& Vincent parameter, $T_{\text {PI }}^{*}$ (Eq. 4) changed by $3658 \%$. The temporal variation in $T_{\text {PI }}^{*}$ overestimates inhibition of photosynthesis by UV, because, as discussed by Pienitz \& Vincent, periods of clear water lead to changes in $T_{\mathrm{PUR}}^{\mathrm{W}}$ that partly compensate increases in $T_{\text {PIR }}^{\mathrm{W}}$ (Fig. 5).

Our quantitative assessment indicates that variations in weighted transparency alone can greatly overestimate the biological effects, more than tenfold in this case. Although we estimate less variability in inhibition than suggested by changes in $T_{\mathrm{PI}}^{*}$ our analysis does not affect the conclusions of Pienitz \& Vincent (2000), i.e. that natural variability in water transparency has a greater influence on water-column photosynthesis and inhibition than even extreme ozone depletion (Arrigo \& Brown 1996, see also Schindler et al. 1996 and Leavitt et al. 1997).

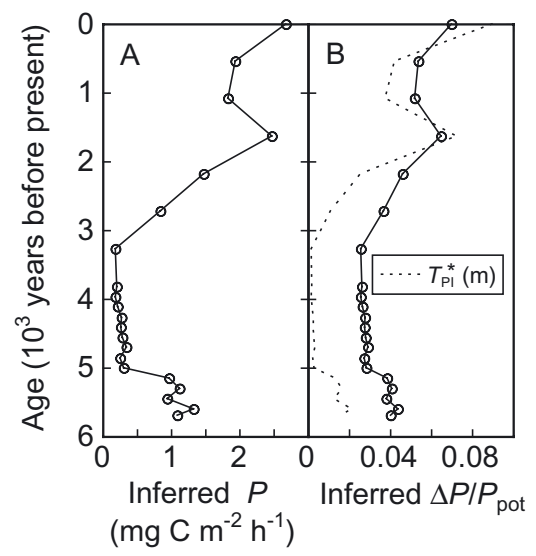

Fig. 4. (A) Time series of inferred photosynthesis $\left(\int P=\right.$ $\int P^{*} \cdot B \cdot P_{\mathrm{S}}^{\mathrm{B}}$, where $\int P^{*}$ is calculated using Eq. 13 , with parameters $b_{n}$ for the sub-Arctic from Table 2) and (B) the proportion of photoinhibition, $\Delta P / P_{\text {pot }}$ (using Eq. 14, with parameters $C_{n}$ for the sub-Arctic from Table 2), in a deep lake with the same evolution of optical properties as Queen's Lake in sub-Arctic Canada. For comparison $T_{\text {PI }}^{*}$ (Eq. 4) based on Pienitz \& Vincent (2000) is shown in Panel B (dashed line) 


\section{CONCLUSIONS}

The use of weighted transparency to describe the transmission of solar radiation through the water column represents an effective tool for describing biological effects as a function of surface-water optical properties. We demonstrated its usefulness by accurately estimating the depth of the $1 \%$ PUR level (Fig. 1A) in a range of water types, encompassing both Case 1, for which optical properties are determined by phytoplankton pigment and derivative products, and Case 2 waters, with an additional CDOM component (Kirk 1994).

Our function of PUR-weighted transparency (Eq. 15) can directly estimate changes in water-column production as influenced by variations in water transparency. The depth of $1 \%$ surface $E_{\mathrm{PUR}}$ expressed as a simple term is an effective substitute for the depth of the euphotic zone in general equations of depthintegrated photosynthesis, as given in Eq. (1). This eliminates a well-recognized error associated with the use of $E_{\mathrm{PAR}}$ (Lewis et al. 1985, Sathyendranath et al. 1989, Laws et al. 1990).

Transparency weighted for photosynthesis-inhibiting radiation $\left(T_{\mathrm{PIR}}^{\mathrm{W}}\right)$ is evaluated in the context of depthintegrated water-column photosynthesis and, in a simple function with $T_{\mathrm{PUR}}^{\mathrm{W}}$, reproduces almost exactly the results of a depth-resolved, spectral model, which includes the effects of UV as described by a biological weighting function. This is, to the best of our knowledge, the first time that UV has been incorporated into depth-integrated equations of photosynthesis (sensu Platt \& Sathyendranath 1993, Behrenfeld \& Falkowski 1997), and it allowed us to transform an indicator of inhibiting radiation (Pienitz \& Vincent 2000) into a predictor of relative photosynthesis and photoinhibition by UV.

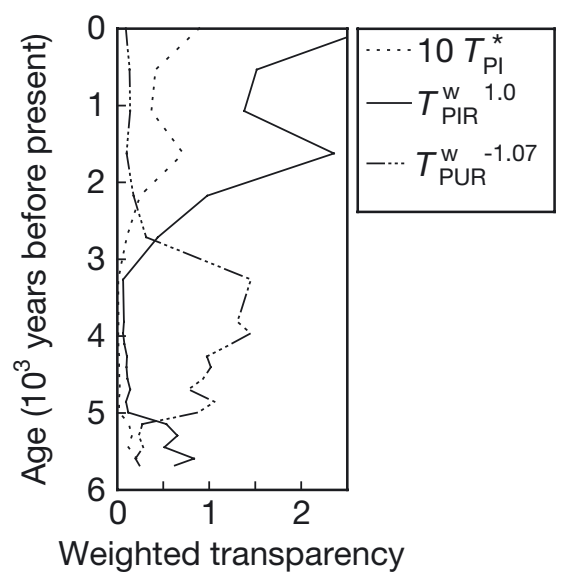

Fig. 5. Time series of $T_{\text {PI }}^{*}$ (Eq. 4, multiplied by 10 to fit scale) based on Pienitz \& Vincent (2000), $T_{\mathrm{PUR}}^{\mathrm{W}}$, and $T_{\mathrm{PIR}}^{\mathrm{W}}$, with the latter 2 raised to their respective powers according to Eq. (14) and parameters $C_{n}$ in Table 2 for the sub-Arctic
The utility of our method is in using 2 simple equations, based on properties at the sea surface (Eqs. 16 \& 17), to replace thousands or millions of depthresolved calculations of subsurface irradiance and biological responses that are based on properties at the sea surface. For many applications, such simple models may provide additional insight. For example, proportional inhibition of water-column photosynthesis is a function of $T_{\mathrm{PIR}}^{\mathrm{W}} / T_{\mathrm{PUR}}^{\mathrm{W}}$ (see also Neale 2001), which is very difficult to generate through a sensitivity analysis using numerical models (Arrigo \& Brown 1996).

This study focuses on the potential influences of variability in water transparency on photosynthesis and its inhibition by UV in the water column. This is accomplished by keeping the other factors constant while examining the effects of varying water transparency. We have extended this analysis to encompass variations in solar irradiance spectra and physiological parameters (Cullen et al. 2000, J. J. Cullen et al. unpubl. data). In a sensitivity analysis, Neale (2001) evaluated the effect of a suite of measured and modeled parameters on the sensitivity of phytoplankton to photoinhibition at solar noon. He concluded that $T_{\mathrm{PIR}}^{\mathrm{W}}$ and the weighting function used for photoinhibition are of similar importance for photoinhibition.

Models of photosynthesis are essential tools for assessing the effects of environmental variability on the physiological responses of phytoplankton (e.g. Arrigo \& Brown 1996, Neale et al. 1998), because only in the rarest of cases can environmental effects on water-column inhibition be determined experimentally. Our parameterizations of photosynthesis and inhibition are shortcuts to describe results of detailed numerical models. While the model used to construct a parameterization requires individual validation of the parameters describing photosynthesis versus irradiance and inhibition versus UV exposure, our method is not dependent on the formulation of the photosynthesis model. Moreover, photosynthesis is but a single example for the application of the weighted transparency concept. The same analysis could be performed on any photochemical or photobiological process for which appropriate weighting functions exist, for example DNA damage (Huot et al. 2000, Pienitz \& Vincent 2000), or photochemical production of DOC (Johannessen \& Miller 2001).

Acknowledgements. This study was funded by NSERC (Research Partnerships, Research Grants), ONR, NOPP, and Environment Canada. We thank W. F. Vincent, who generously provided data and many suggestions. Marine irradiance and chlorophyll data were kindly provided by M. Mallonnee, L. Harding and W. L. Miller. The manuscript was improved by considering the comments of $\mathrm{C}$. Brown and 3 anonymous reviewers. 


\section{LITERATURE CITED}

Arrigo KR (1994) Impact of ozone depletion on phytoplankton growth in the Southern Ocean: large-scale spatial and temporal variability. Mar Ecol Prog Ser 114:1-12

Arrigo KR, Brown CW (1996) Impact of chromophoric dissolved organic matter on UV inhibition of primary productivity in the sea. Mar Ecol Prog Ser 140:207-216

Arrigo KR, Lubin D, van Dijken GL, Holm-Hansen O, Morrow E (2003) Impact of a deep ozone hole on Southern Ocean primary production. J Geophys Res Oceans 108: no. C5.10.1029/2001JC001226, 2003

Baker KS, Smith RC (1982) Bio-optical classification and model of natural waters. Limnol Oceanogr 27:500-509

Behrenfeld MJ, Falkowski PG (1997) A consumer's guide to phytoplankton primary productivity models. Limnol Oceanogr 42:1479-1491

Boucher NP, Prézelin BB (1996) Spectral modeling of UV inhibition of in situ Antarctic primary production using a field derived biological weighting function. Photochem Photobiol 64:407-418

Cullen JJ, Neale PJ, Lesser MP (1992) Biological weighting function for the inhibition of phytoplankton photosynthesis by ultraviolet radiation. Science 258:646-650

Cullen JJ, Davis RF, Huot Y, Lehmann MK (2000) Quantifying effects of ultraviolet radiation in surface waters. In: Ocean optics XV: conference proceedings on CD-ROM. Prestige Publishing, Alexandria, VA

Gregg WW, Carder KL (1990) A simple spectral solar irradiance model for cloudless maritime atmospheres. Limnol Oceanogr 35:1657-1675

Huot Y, Jeffrey WH, Davis RF, Cullen JJ (2000) Damage to DNA in bacterioplankton: a model of damage by ultraviolet radiation and its repair as influenced by vertical mixing. Photochem Photobiol 72:62-74

Johannessen SC, Miller WL (2001) Quantum yield for the photochemical production of dissolved inorganic carbon in seawater. Mar Chem 76:271-283

Kirk JTO (1994) Light and photosynthesis in aquatic ecosystems. Cambridge University Press, Cambridge

Laws EA, DiTullio GR, Carder KL, Betzer PR, Hawes S (1990) Primary production in the deep blue sea. Deep-Sea Res Part A 37:715-730

Leavitt PR, Vinebrooke RD, Donald DB, Smol JP, Schindler DW (1997) Past ultraviolet radiation environments in lakes derived from fossil pigments. Nature 388:457-459

Lehmann MK, Davis RF, Huot Y, Cullen JJ (2000) Biologically weighted transparency: a predictor for water column photosynthesis and its inhibition by ultraviolet radiation. In: Ocean optics XV: conference proceedings on CDROM. Prestige Publishing, Alexandria, VA

Lewis MR, Warnock RE, Platt T (1985) Absorption and photosynthetic action spectra for natural phytoplankton populations: implications for production in the open ocean. Limnol Oceanogr 30:794-806

Markager S, Vincent WF (2001) Light absorption by phytoplankton: development of a matching parameter for algal photosynthesis under different spectral regimes. J Plankton Res 23:1373-1384

Morel A (1978) Available, usable, and stored radiant energy

Editorial responsibility: Otto Kinne (Editor),

Oldendorf/Luhe, Germany in relation to marine photosynthesis. Deep-Sea Res 25: $673-688$

Morel A (1988) Optical modelling of the upper ocean in relation to its biogenous matter content (Case I waters). J Geophys Res 93:10749-10768

Morel A (1991) Light and marine photosynthesis: a spectral model with geochemical and climatological implications. Prog Oceanogr 26:263-306

Morel A, Berthon JF (1989) Surface pigments, algal biomass profiles, and potential production of the euphotic layer: relationships reinvestigated in view of remote-sensing applications. Limnol Oceanogr 34:1545-1562

Morrow JH, Booth CR (1997) Instrumentation and methodology for ultraviolet radiation measurements in aquatic environments. In: Häder DP (ed) The effects of ozone depletion on aquatic ecosystems. R. G. Landes, Austin, p 31-44

Neale PJ (2000) Spectral weighting functions for quantifying effects of UV radiation in marine systems. In: de Mora S, Demers S, Vernet M (eds) The effects of UV radiation in the marine environment. Cambridge University Press, Cambridge, p 72-100

Neale PJ (2001) Modeling the effects of ultraviolet radiation on estuarine phytoplankton production: impact of variations in exposure and sensitivity to inhibition. J Photochem Photobiol B Biol 62:1-8

Neale PJ, Davis RF, Cullen JJ (1998) Interactive effects of ozone depletion and vertical mixing on photosynthesis of Antarctic phytoplankton. Nature 392:585-589

Pienitz R, Vincent WF (2000) Effect of climate change relative to ozone depletion on UV exposure in subarctic lakes. Nature 404:484-487

Platt T, Sathyendranath S (1993) Estimators of primary production for the interpretation of remotely-sensed data on ocean color. J Geophys Res 98:14561-14596

Ryther JH, Yentsch CS (1957) The estimation of phytoplankton production in the ocean from chlorophyll and light data. Limnol Oceanogr 2:281-286

Sakshaug E, Johnsen G, Andersen K, Vernet M (1991) Modeling of light-dependent algal photosynthesis and growth: experiments with Barents Sea diatoms Thalassiosira nordenskioeldii and Chaetoceros furcellatus. Deep-Sea Res 38:415-430

Sathyendranath S, Platt T, Caverhill CM, Warnock RE, Lewis MR (1989) Remote sensing of oceanic primary production: computations using a spectral model. Deep-Sea Res 36: 431-453

Schindler DW, Curtis PJ, Parker BR, Stainton MP (1996) Consequences of climate warming and lake acidification for UV-B penetration in North American boreal lakes. Nature 379:705-708

Smith RC, Baker KS, Holm-Hansen O, Olson RS (1980) Photoinhibition of photosynthesis in natural waters. Photochem Photobiol 31:585-592

Talling JF (1957) The phytoplankton population as a compound photosynthetic system. New Phytol 56: 133-149

Vincent WF, Laurion I, Pienitz R (1998) Arctic and Antarctic lakes as optical indicators of global change. Ann Glaciol 27:691-696

Submitted: July 4, 2003; Accepted: October 21, 2003

Proofs received from author(s): March 15, 2004 